\title{
Implementation of Life Cycle Costing in Enhancing Value for Money of Projects
}

\author{
F.A.Mohd Rahim, S.A.Muzafar, N.Zakaria, N.Zainon, P.A.Johari \\ Project Management, Procurement and Economics Research Group \\ Centre for Building, Construction \& Tropical Architecture \\ Faculty of Built Environment, \\ University of Malaya, 50603 Kuala Lumpur \\ *azli@um.edu.my
}

\begin{abstract}
Life Cycle Costing (LCC) is becoming more important since long-term building owners and clients have begun to demand an estimate evidence of what their cost of ownership will accrue to.LCC is a sophisticated approach to estimating the cost incurred in the future and produce comprehensive costing information. Despite growing awareness of LCC practices and concepts among practitioners, actual implementation of this technique is slow to take hold, especially in the Malaysian construction industry. The concept of LCC seems poorly understood; thus, there is a need to overcome this deficiency in order to successfully deliver LCC in the construction industry. This paper aims to study the implementation of LCC, with the main focus on the design stage towards enhancing overall value for money. The relationships between the factors of LCC implementation that can contribute to project's value were investigated. The results of this study revealed several critical factors of LCC that should be taken into account to raise awareness and promote LCC implementation at the design stage among the construction practitioners. The challenges to implementation are also discussed in this study.
\end{abstract}

Keywords: Life cycle costing, value for money, project value, value management

\subsection{INTRODUCTION}

The construction industry is a crucial sector of economic activity that differs from other industries as it does not produce in bulk at one time but has its own development value (Tanyer, 2004). In most countries, construction activity constitutes about 6 to 9 percent of the gross domestic product (GDP) and constitutes more than half of the fixed capital formation as infrastructure and public utility capital works that are required for economic development (Chitkara, 2009). Life Cycle Costing (LCC) approach in a construction project is particularly very important in that it judges design alternatives, which is fundamental to meet the required performance goals of a building by taking into account initial capital costs, operation and repair costs, as well as the life of the building itself (Sterner s, 2003; Sacks et al., 2012). LCC helps in monitoring cost performance over the economic life span of a building. Therefore the implementation of LCC in the construction industry is significantly important in the construction of structures and infrastructure projects that will minimize risks of loss to the industry and the country (Akasah \& Rum, 2011). 
Life Cycle Costing (LCC) is a method for economic evaluation which considers the costs applicable to the total life of a project. Rangelova \& Traykova (2014) have defined LCC as "the present value of the total cost of the project/asset over its entire operating life and includes the initial capital and construction costs, operating and maintenance costs and the cost or the benefit of eventual disposal of the asset". Life Cycle Costing (LCC) is an evaluation tool in enhancing the value for money of construction projects. Grimsey \& Lewis (2004) defined value for money (VFM) as the optimum combination of whole life cycle costs, risks, completion time and quality in order to meet specific requirements of a project. HM Treasury (2006) of the UK has published a guideline entitled "Value for Money Assessment Guidance" which indicates that there are three stages in assessing the value for money ofa potential project, namely the programme level assessment, the project level assessment and the procurement level assessment.

LCC serves as a far more accurate analysis of the long-term cost effectiveness of a project (Boussabaine \& Kirkham, 2004) as it concentrates on overall cost rather than initial cost only. If properly carried out, LCC will deliver benefits such as (1) transparency of future cost of operations, (2) improve ability to plan future expenditure, (3) increase awareness of total cost, (4) improve ability to manipulate and optimise future costs at the design stage, (5) higher chance to achieve and obtain better value for money (VFM) in project, (6) provide competitive alternatives evaluation and (7) better performance trade-offs against cost (Langdon, 2005).Life Cycle Costing (LCC) approach can be applied throughout the project entire life (Ashworth \& Hogg, 2000) but LCC will be most effective if it is used in the early development phases of a project, such as in the design phase. The reason is that most of the operating costs which accumulate during a lifetime of a building are determined at a design phase (Bogenstätter, 2000). During this stage, factors and maintenance costs of a project are accounted to obtain a more accurate LCC projection (Akashah \& Rum, 2011). Optimal benefits will be obtained on larger and more complex projects (Rangelova \& Traykova, 2014).

Despite the benefits of using LCC, its usage is only found to be extensive in procuring building assets (TRADA Technology, (2008) as cited by Akasah \& Rum, 2011). However, the unfamiliarity of LCC and uncertainty of the benefits gained by implementation of LCC in the construction industry were seen to be the general problems (Lindholm \& Suomala, 2007). Ashworth \& Hogg (2007) stated that lack of understanding of the elements of LCC has led to the lack of enthusiasm of clients, consultants and even contractors to include running costs during the design process of a project. This paper, therefore, aims to explore the benefits of implementing Life Cycle Costing (LCC) approach in terms of project's value for money focusing on the design phase of a construction project. The specific objectives of the study include to:

- identify the critical factors that could enhance value for money of projects when using LCC approaches;

- examine the relationship between LCC's factors with project's value for money; and

- identify the challenges in implementing LCC during design stage of a construction project.

\subsection{LIFE CYCLE COSTING (LCC)}

Life Cycle Costing (LCC) technique works as the economic analysis of competing design proposals by including all significant costs of ownership over the life of a building, usually expressed in equivalent dollars, which is specified by an analytical study and experience in estimating the total costs on yearly basis (Langston 2005; Kirkham, 2007). Barringer (2003) described LCC as a tool for assessing the total cost performance of an asset over time including the acquisition, operating, maintenance and disposal cost. It is also defined as the total cost of project measured over a period of financial interest of the clients (Flanagan \& Jewell, 2005). It is one of several methodologies that can be used to account and provide costing in a more comprehensive way by involving systematic consideration of all relevant costs and revenues associated with acquisition and ownership of an asset or a project (Cole \& Sterner, 2000). 
According to Olanrewaju (2013), Life Cycle Costing is concerned with the relationship of initial cost and other future based cost. In other words, it is a comparison to find out how much additional capital expenditure is warranted today in order to achieve future benefits over the entire life of the project. LCC is also being referred to as whole life cycle or cost-in-use (Olanrewaju, 2013). LCC serves as an economic evaluation technique to select various options in terms of design and building components to meet client's objective in achieving better VFM from the building procured and used (Langdon, 2005). The key motivation to use LCC is to increase the likelihood to reduce the expenses during operation even if it takes to invest more during the early stage of a project (Sterner, 2000). Investing slightly more in for capital costs might lead to significantly reduced maintenance and operating costs in the future, thus suggesting that better value can be secured not only through lowest capital cost.The practice of LCC analysis needs to be enhanced among the construction practitioners to discover strategies that can encourage greater usage, especially during the design stage.

The main objective of implementing LCC is to figure out and determine the best way to reduce building ownership costs in order to achieve a financially viable investment (Highton, 2012). In this aspect, LCC acts as a decisionmaking and management tool. Che Mat (2002) describes that LCC approach is effective in the decision making process in four main ways. Firstly, it identifies the total cost undertaken in asset acquisition. Secondly, it facilitates an effective choice between alternative methods by taking into consideration various alternatives which display different capital and running costs. Subsequently, LCC is a management tool that details out all costs associated with capital, running and replacement costs of the building or components within that building. All of these can be summarized as the decision to invest should be made on the total LCC of an asset and not on the basis of initial capital cost alone, because the future is as important as those incurred in the capital acquisition. According to Akasah \& Rum (2011), LCC adds to all the costs of different options over their life period and enables an evaluation on a common basis for the period of interest, thus enabling decisions to be made in the path full of cost implications.

Ashworth and Hogg (2000) found that the usage of LCC is the most effective in the design stage in terms of overall cost consequences of construction, particularly at the conceptual and preliminary design stages whereby changes are able to be made easily and resistance to such changes is less likely to occur. This was supported by Che Mat (2002) and Clift (2003) who suggested that the implementation of LCC isto be made as early as possible to obtain the maximum effect. It is therefore important to ensure that decisions made at the design stage are precise, as such decisions have profound impacts on the LCC of the building (Flanagan \& Jewell, 2005; Ellingham \& Fawcett, 2006; Ashworth, 2010; cited in Highton, 2012).

\subsection{Value for Money (VFM)}

Value for Money (VFM) can be described as the optimum composition of whole-life cost and quality to satisfy user's requirement. The life cycle costs throughout an asset's life are broadly identified as a much more reliable VFM indicator rather than awarding contracts on the basis of lowest price tendered for construction works (Langdon, 2005). In other words, VFM can be determined via the relationship between long-term costs and the benefit achieved by the client.

MacDonald et al. (2012) defined VFM in two different ways. Firstly, VFM is defined as the recognition of value that has various dimensions outboard the conventional perspective of economic which involves social and environmental objectives as well as intangible characteristics including quality of relationship, leadership, learning, reputation and trust. Subsequently, the more sophisticated approach of VFM focuses on the whole project life cycle and does not emphasize merely on the benefits delivered during construction stages. On the other hand, Ashworth (2004) stated that value is "a comparative term that is used to express the worth of an item, often in the context of other similar or comparable items". 
Langdon \& Everest (2004) had stated that VFM in construction field involves completing a project to specified time, cost and a level of quality as well as meeting the project requirements. They also added that investment in design quality at an the early stage can deliver better VFM and meet user needs over the lifetime of the project as well as providing benefits towards the environment. Ashworth (2004) supported the statement by acknowledging that it is well worthwhile to invest a little more in capital cost if it will eventually result in gaining more value that would offset the extra cost expended earlier.

\subsection{Life Cycle Costing and Value Management}

Che Mat (2002) defined Value Management (VM) as "a rigorous, systematic effort to improve the value and optimize the cost of projects, facilities and systems". VM has the ability to generate cost improvements without sacrificing the required performance levels. The function of facilities, systems, process and equipment can be analysed through value management in order to deliver the function required at the lowest total cost of ownership.Life Cycle Costing (LCC) may be utilized during the VM study to develop the lowest total cost of ownership. While value managementfocuses mainly on the functional analysis and elimination of unnecessary functions for the determination of the least cost course of action which meets the true functional requirement (Che Mat, 2002), LCC focuses on the determination of several courses of action that would be least in cost throughout a specific time frame. Therefore, a VM can be used to complement life cycle analysis whereby selected alternatives cannot be implemented if they exceed the allocated budget for a construction project (Figure 1).

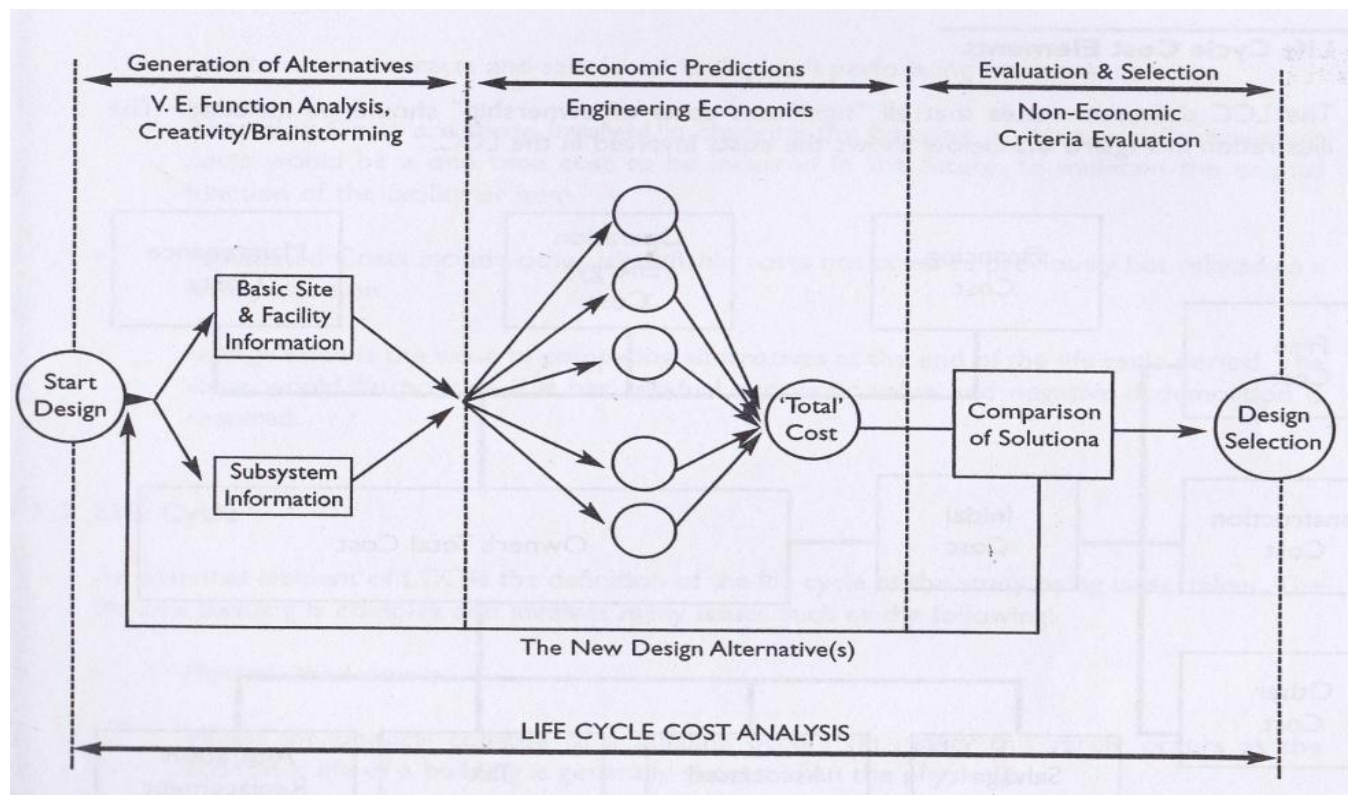

Figure 1: Interrelationship of VM and LCC (adapted from Dell 'Isola \& Kirk (1981) as cited in Che Mat, 2002).

There are several factors in Life Cycle Costing (LCC) implementation that can contribute to the overall values of a construction project. The factors are summarized in the Table1.

Table 1: Critical factors of LCC implementation that contribute to project's value

\begin{tabular}{ll}
\hline \multicolumn{1}{c}{ Factors } & \multicolumn{1}{c}{ Description } \\
\hline $\begin{array}{l}\text { Application of LCC at design } \\
\text { stage }\end{array}$ & $\begin{array}{l}\text { Money spent on good design can be saved many times over in the construction } \\
\text { and maintenance. }\end{array}$ \\
\hline $\begin{array}{l}\text { Involvement of stakeholders in } \\
\text { preparing LCC at design stage }\end{array}$ & $\begin{array}{l}\text { Contribution from the stakeholders in terms of their knowledge and experience } \\
\text { can produce unique solutions in preparing LCC. }\end{array}$ \\
\hline Teamwork in LCC preparation & The client and integrated project team need to work together so that more accurate \\
\hline
\end{tabular}




\begin{tabular}{ll}
\hline at design stage & $\begin{array}{l}\text { and robust estimates can be prepared, which can be benchmarked against other } \\
\text { schemes and clients cost to ensure that VFM is achieved (Achieving Excellence in } \\
\text { Construction, 2003). }\end{array}$ \\
\hline $\begin{array}{l}\text { Determination of cost } \\
\text { implication for design decision } \\
\text { when preparing LCC }\end{array}$ & $\begin{array}{l}\text { Better decision can be made based on the lowest running cost of a design } \\
\text { alternative although higher capital investment is required at times. }\end{array}$ \\
\hline $\begin{array}{l}\text { Indication of design } \\
\text { deficiencies while preparing } \\
\text { LCC at design stage }\end{array}$ & $\begin{array}{l}\text { Design deficiencies can be uncovered and corrected without compromising the } \\
\text { quality and performance of a project which in turn, achieve significant savings in } \\
\text { the future. }\end{array}$ \\
\hline $\begin{array}{l}\text { Carry out LCC analysis along } \\
\text { with Value Management study }\end{array}$ & $\begin{array}{l}\text { VM is a systematic and holistic approach that helps to achieve the required } \\
\text { function of a facility or system at the lowest TCO. }\end{array}$ \\
\hline
\end{tabular}

\subsection{METHODOLOGY}

The practitioners' views on LifeCycle Costing (LCC) in enhancing value for money of construction projects were solicited by way of a questionnaire survey.The purpose of the survey was to explore construction practitioners' perspectives about LCC factors that contribute to the overall construction projects' value for money. The questionnaire survey highlighted the most effective stage in implementation of LCC in projects and also on the parties involved in LCC calculation at design stage. In addition, the respondents were asked about the influence level of a series of variables towards project's values for money with regards to LCC. The challenges in implementing LCC during the design stage of projects are also emphasized in the survey.

The survey was conducted by sending the questionnaires to a selected group of quantity surveyors, value managers, contractors, developers and project managers involved in a variety of projects within Klang Valley. The respondents were chosen from various databases, namely, the Real Estate and Housing Developers' Association of Malaysia (REHDA), the Institute of Value Managers Malaysia (IVMM), the Board of Quantity Surveyors Malaysia (BQSM), and the Construction Industry Development Board of Malaysia (CIDB). The number of questionnaires sent out was 200 and the response rate was $26.5 \%$. It is significant in respect of the reliability of the response rate that $94 \%$ of the responses received were from the parties involved inconstruction projects namelyproject managers, engineers, quantity surveyors and contractors.

Although not all of the respondents may have hands-on experience with LCC in enhancing projects' value for money, the selected respondents were all practitioners that were involved with LCC in some way. Some of them were involved through the way of doing research, others may have participated in implementing LCC in projects, and some were preparing to be involved with future LCC projects. Therefore, their responses were believed to be as valuable as those respondents have actual hands-on experience with LCC. Once again this reassures the value and reliability of the findings. Responses from various parties involved in projects will indicate the familiarity and current implementation of LCC in the Malaysian construction industry. The -responses were scaled on a Likert scale of 1 to 5, in which the scales indicate the following: 1 -"strongly disagree" or "never occurred", 2 - "disagree" or " rarely occurred", 3 - "neutral" or "occasionally occurred", 4 - "agree" or "often occurred" and 5 -"strongly agree" or "always occurred".

\subsection{DATA ANALYSIS \& DISCUSSION}

Frequency analysis was carried out using frequency table to represent the values for each variable given by the respondents. Then, correlation analysis was adopted in this research to measure the relationship strength between these variables.Relative Importance Index (RII) was also used to compute the relative importance or rankings of the variables. The score for each variable was calculated by totalling up the scores indicated by the respondents (Fagbenle et al., 2004). Mean score ranking technique was used to calculate the mean score for each LCC critical factors, which was then used to determine its relative ranking in descending order of importance. These rankings 
made it possible to triangulate the relative importance of the LCC critical factors to the construction projects' value for money.

\subsection{LCC implementation}

Majority of the respondents agreed that LCC approach is most effective when applied in the design stage (56.6\%) of construction projects (Figure 2). This is aligned with the study by Bogenstätter (2000) which stated that most of the operating costs that were accumulated during a lifetime of a building are determined at the design phase. During the design stage, factors and maintenance costs of a project are accounted to obtain a more accurate LCC projection (Akashah \& Rum, 2011). The rest of the respondents believe that LCC should have commenced at the inception phase $(24 \%)$, during the construction period (15\%), with another $4 \%$ implementing LCC during operation and maintenance phase of a project.

LCC is also well-known in construction projects as a decision-making tool (Figure 3). 68\% of the respondents have experienced using LCC as the decision-making tool when taking consideration the various alternatives costing methods which display different capital and running costs. In this aspect, LCC has the ability to figure out and determine the best way to reduce building ownership costs in order to achieve a financially viable investment (Highton, 2012). The rest of the respondents rarely used LCC (15\%) when making decision in projects due to the management conflicts, while the other $17 \%$ of them never have any experience with LCC as decision-making tool because of their lack of awareness towards knowledge and practices of LCC in their organisations.

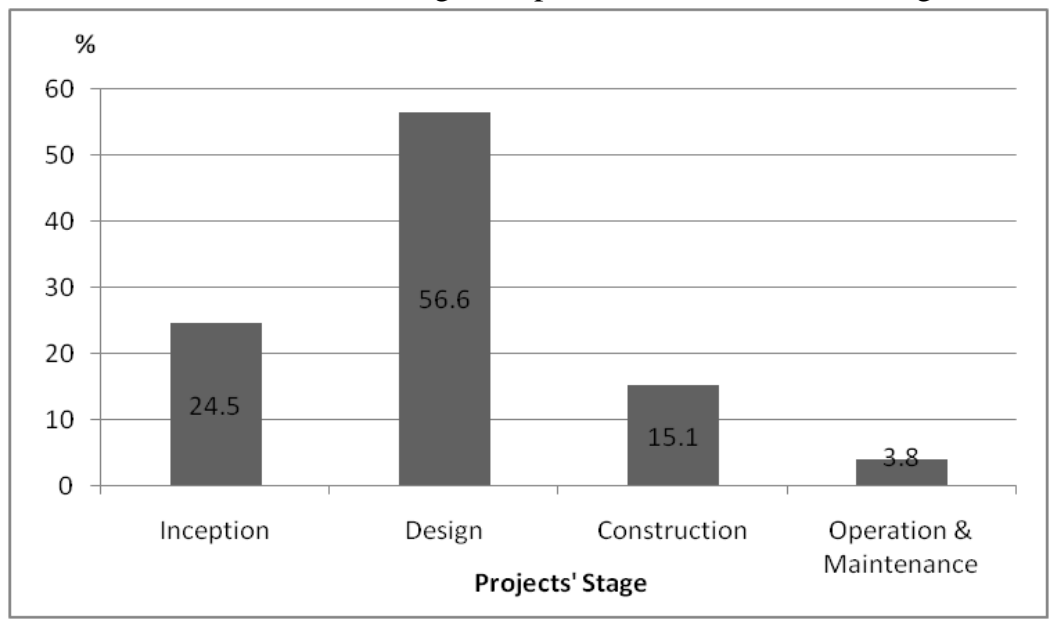

Figure 2: The most effective stage of LCC implementation in projects

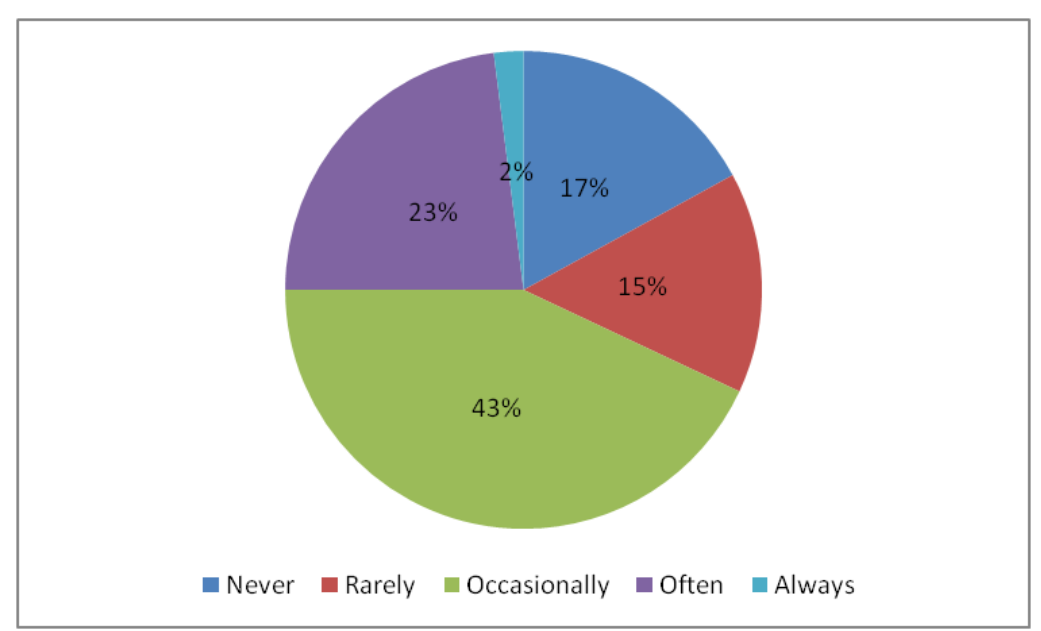

Figure 3: The application of LCC as decision-making tool in projects 
The utilization of LCC with Value Management (VM) in construction projects shows positive correlation. Most of the respondents have experienced in applying LCC during VM study, with the aim to develop the lowest total cost of ownership of the projects. From Figure 4, 36\% of respondents often used LCC in their VM analysis of the projects,30\% of them occasionally used them and the other $4 \%$ always adopting LCC in the VM for the projects. Value management has the ability to generate cost improvements without sacrificing the required performance levels and can be used to complement life cycle analysis whereby selected alternatives cannot be implemented if they exceed the allocated budget for a construction project (Che Mat, 2002).

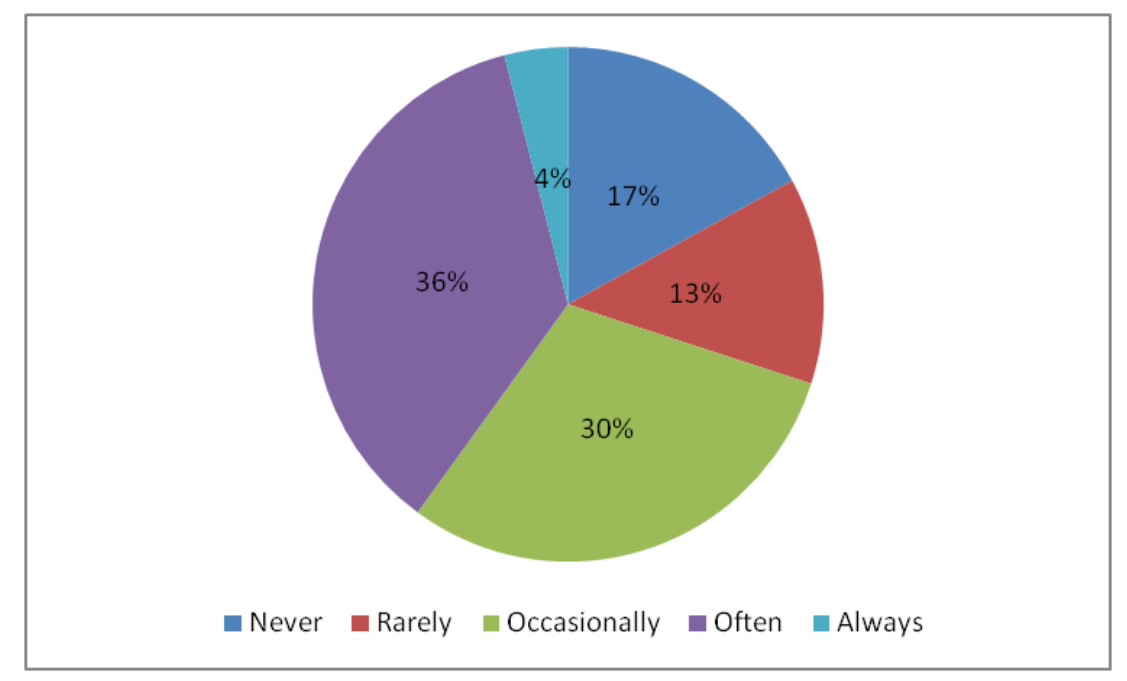

Figure 4: The adoption of LCC along with Value Management

\subsection{Value for Money}

In order to indicate the influence level of the factors that can contribute to the project's value for money, Pearson correlations was used tocalculate the relationship between the variables. The analysis shows 19 of the 21 pairs of the variables that were significantly correlated. In general. Almost all the variables are moderately correlated to each other. The strongest positive correlation was between determination of design decision and teamwork in preparing LCC at design stage $(\mathrm{r}=0.771)$. This means that teamwork needs to be incorporated to determine the design decision when preparing LCC at the design stage of a project.

On the other hand, the application of LCC at the design stage was strongly correlated with teamwork $(r=0.712)$ and indication of design deficiencies while preparing LCC at the design stage $(r=0.741)$. Moreover, the variable of carrying out LCC analysis along VM study shows a positive correlation with teamwork in LCC preparation ( $\mathrm{r}=$ $0.586)$, determination of the cost implication for design decision ( $\mathrm{r}=0.494)$ and indication of design deficiencies while preparing LCC ( $\mathrm{r}=0.628)$; all three are moderately correlated. Such variables serve as key drivers for the implementation of LCC at design stage, hence contribute to the enhancement of project value. Additionally, Che Mat (2002) stated that LCC can be used along with Value Management to develop the lowest cost of ownership, so it is important to determine the cost implication for design decision when preparing LCC to ensure that the best alternative is selected for a project.

Relative Importance Index (RII) which is used to compute the relative importance or ranking of the variables, was constructed to see the rank of the factors that lead towards enhancing the project's value for money. Analysis has shown that the application of LCC at design stage is the most important factor with RII $=0.766$. It is followed by the teamwork in preparation of LCC at design stage (RII=0.740), carrying out LCC analysis along with value 
management (VM) study and determination of cost implication for design decision, both having the same index of $\mathrm{RII}=0.728$. In this study, teamwork refers to the relationship between each party in the design team and the client. Every member of the design team needs to work together in generating ideas as well as contributing their experience and knowledge in preparing LCC at the design stage. Poor human relation, misunderstanding and friction often lead to occurrence of unnecessary cost. (F.A.Rahim et al, 2014)

Table 2: LCC critical factors that are very significant in enhancing project's value

\begin{tabular}{lcc}
\hline \multicolumn{1}{c}{ Factors } & RII & Rank \\
\hline Application of LCC at design stage. & 0.766 & 1 \\
Teamwork in LCC preparation at design stage. & 0.740 & 2 \\
Determination of cost implication for design decision when preparing LCC. & 0.728 & 3 \\
Carry out LCC analysis along with the Value Management study. & 0.728 & 3 \\
Indication of design deficiencies while preparing LCC at design stage. & 0.687 & 5 \\
Involvement of stakeholders in preparing LCC at design stage. & 0.653 & 6 \\
Investment of LCC tools. & 0.619 & 7 \\
\hline
\end{tabular}

(F.A.Rahim et al, 2014)

\subsection{Challenges in implementing LCC at design stage}

Majority of the respondents (49\%) agreed that lack of knowledge of LCC concept among construction practitioners is one of the challenges in implementing LCC at design stage.Lack of LCC data and non existence of standard methods in calculating LCC in construction projects were the crucial barriers to implementation of LCC. Table 3 summarized the significant challenges in implementing LCC at design stage of construction projects. Based on the RII analysis, the main challenges encountered in implementing LCC at the design stage are the unavailability of LCC data and lack of direct involvement of stakeholders (RII=0.736). This portrays that LCC data are made unavailable for the reference of construction practitioners, making it difficult to carry out LCC. Besides that, the unavailability of standard in calculating LCC makes it more difficult to implement LCC. Lack of knowledge of LCC concept and shortage of qualified and experienced consultants of LCC in construction industry directly worsen the situation.

Table 3: Challenges in implementing LCC at design stage

\begin{tabular}{lcc}
\hline \multicolumn{1}{c}{ Challenges } & RII & Rank \\
\hline Unavailability of LCC data. & 0.736 & 1 \\
Lack of direct involvement of stakeholders. & 0.736 & 1 \\
Lack of standard method in calculating LCC. & 0.728 & 3 \\
Shortage of qualified and experienced consultant in LCC. & 0.725 & 4 \\
Lack of knowledge of LCC concept among the construction practitioners. & 0.717 & 5 \\
Unfamiliar with design-to-cost concept. & 0.683 & 6 \\
Unclear benefits of LCC to management. & 0.675 & 7 \\
Unreliability in making decision. & 0.653 & 8 \\
Cost to be paid to designer in conducting LCC. & 0.653 & 8 \\
Difficulties in determining cost elements for different alternatives. & 0.653 & 8 \\
Limited IT tools to assist LCC & 0.645 & 11 \\
\hline
\end{tabular}

\subsection{CONCLUSION}

As with any other management tools, Life Cycle Costing (LCC) began to be utilized in order to favour financial and economic assessment of design alternatives with the objective to identify the best way to minimize the ownership cost of an asset to accomplish a financially viable investment. LCC can be used in all phases of a building life, but it 
is believed that LCC implementation at the design phase will achieve the full effectiveness. Among the significant factors to be considered when implementing LCC at the design stage of a construction project are the involvement of clients, design team participation and time value of money variables. In addition, LCC is well-known as a reliable indicator for value for money (VFM) as it serves long-term benefits to the parties involves. This study has found that the determination of design decision and teamwork in preparing LCC at design stage has the strongest correlation among all variables. By utilizing the RII, the result shows that application of LCC at design stage is the main driver in enhancing the project's value for money. As for the challenges in LCC implementation, the unavailability of LCC data and lack of direct involvement from stakeholders are the crucial barriers in any construction projects. This study has shown that construction practitioners are actually aware of the importance of LCC in enhancing projects' value for money,but due to various factors, its application in Malaysian construction industry is still lacking. The slow development of LCC usage is due to the lack of knowledge regarding LCC concept and its importance towards the construction projects. This study opens opportunity for future studies to explore further on how LCC can statistically assist the financial forecast, particularly the cash flow. This will be beneficial to assist all parties involved in projectsfor the preparation of the budget planning at the early stage of projects implementation.

\subsection{ACKNOWLEDGEMENT}

This research is supported by the University of Malaya Research Grant, Function of Life cycle costing in enhancing value for money of projects (UMRG-RG133/1ISUS), and Whole life cycle costing for sustainable construction (RP007B-13SUS).

\subsection{REFERENCES}

Akasah, Z.A. \& Rum, N.A.M. (2011). Implementing Life Cycle Costing in Malaysia Construction Industry: A Review. Proceeding of International Building and Infrastructure Conference, 7-8 June, 2011

Ashworth, A. (2004). Cost Studies of Buildings.4th Ed.United Kingdom: Longman Group.

Ashworth, A., and Hogg, K. (2000).Added Value in Design and Construction. England: Pearson Education Limited.

Ashworth, A. and Hogg, K.W. (2007). Practice and Procedure for the Quantity Surveyor. $12^{\text {th }}$ Ed. Oxford: Blackwell publishing

Barringer, H.P. (2003). Life Cycle Cost Summary. Proceeding of International Conference of Maintenance Societies, Maintenance Engineering Society of Australia, Technical Society of the Institution of Engineers, Australia.

Bogenstätter, U. (2000). Prediction and Optimization of Life-Cycle Costs in Early Design. Building Research and Information 28(5/6):376-386.

Boussabaine, H.A., and Kirkham, R.J. (2004). Whole Life Cycle Costing: Risk and Risk Responses. Oxford: Blackwell Publishing Ltd.

Che Mat, M.M. (2002). Value Management: Principles and Applications. $1^{\text {st }}$ Ed.Petaling Jaya: Prentice Hall.

Chitkara, K.K. (2009). Construction Project Management: Planning Scheduling and Controlling. New Delhi: Tata McGraw-Hill.

Clift, M. (2003). Life-cycle costing in the construction sector. Retrieved March 17, 2013 from http://www.bvsde.paho.org/bvsaia/fulltext/costing.pdf

Cole, E.J., and Sterner, E. (2000). Reconciling Theory and Practice of Life-Cycle Costing. Building Research and Information28(5/6):368-375.

F.A.Rahim, S.A.Muzaffar, N.S. Mohd Yusoff, N. Zainon, C. Wang. (2014). Sustainable Construction Through Life Cycle Costing. Journal of Building Performance; Vol 5; Issue 1; pp 84-94

Flanagan, R., and Jewell, C. (2005). Whole Life Appraisal: for construction. $1^{\text {st }}$ Ed.Oxford: Blackwell Publishing Ltd.

Grimsey, D. and Lewis, M. (2004). Discount Debates: Rates, Risk, Uncertainty and Value for Money in PPPs. Public Infrastructure Bulletin 3 (March):4-7. 
Highton, J. (2012). Life cycle costing and procurement of new building: the future direction of the construction industry. Public Infrastructure Bulletin, 1(8), Article 5. Retrieved on March 2, 2013 from http://epublications.bond.edu.au/pib/vol1/iss8/5.pdf

HM Treasury (UK) (2006). Value for Money Assessment Guidance, HM Treasury. Retrieved February 6, 2013 from http://www.hm-treasury.gov.uk/ppp_vfm_index.htm

Kats, G.H. (2003). Green Building Costs and Financial Benefits. Massport: Massachusetts Technology Collaborative.

Kirkham, R. (2007). Ferry and Brandon's Cost Planning of Buildings. ${ }^{\text {th }}$ Ed. Oxford: Blackwell Publishing Ltd.

Langdon, D. (2005). Life Cycle Costing as acontribution to Sustainable Construction. Retrieved February 6, 2013, from

http://ec.europa.eu/enterprise/sectors/construction/files/compet/life_cycle_costing/guidance_case_study_en. pdf

Langdon, D. and Everest (2004). Getting Value for Money from construction projects through design. Retrieved

March 17, 2013 from

http://webarchive.nationalarchives.gov.uk/20110118095356/http://www.cabe.org.uk/files/getting-value-formoney-from-construction-projects-through-design.pdf

Langston, C.A. (2005). Life-cost Approach to Building Evaluation. $1^{\text {st }}$ Ed.Sydney: Butterworth Heinemann.

Lindholm, A. and Suomala, A. (2007). Learning by Costing: Sharpening Cost Image Through Life Cycle Costing?. International Journal of Productivity and Performance Management56(8):651-672.

MacDonald, C., Walker, D.H.T., and Moussa, N. (2012). Value for Money in Project Alliances. International Journal of Managing Project in Business 5(2):311-324.

Olanrewaju, A.L.A. (2013). A Critical Review of Value Management and Whole Life Costing On Construction Projects. International Journal of Facility Management 4 (1):1-12.

Rangelova Fantina \& Traykova Marina (2014). Assessment of the existing prefabricated RC residential buildings in Bulgaria and recommendations for their rehabilitation and strengthening. Proceeding of the Second International Conferences on Advances In Civil, Structural and Mechanical Engineering- CSM 2014: 189193.

Sacks, A., Nisbet, A., Ross, J., and Harinarain, N. (2012). Life Cycle Cost Analysis: A Case Study of Lincoln on the Lake. Journal of Engineering, Design and Technology 10(2):228-254.

Sterner, E. (2000). Life-cycle Costing and Its Use in the Swedish Building Sector. Building Research and Information 28(5/6):387-393.

Tanyer, A.M. (2004). Developing evaluation criteria for computer integrated construction: A usability analysis with end users. Paper presented at the World IT Conference for Design and Construction (INCITE), Langkawi, Malaysia. 